\title{
A database for the Devonian faunas of New York state
}

\section{DLKFossil@gmail.com}

Daniel Krisher

\section{Introduction}

Over 150 years of research has generated a wealth of data concerning the Devonian taxa and

biostratigraphy of New York. The use of this data has been hampered by its publication in a multiplicity of journals spanning many years. To address the lack of a comprehensive guide to the Devonian taxa and biostratigraphy of New York a database has been created which aggregates all taxonomic and biostratigraphic data in a single source.

\section{Data}

Data sources

Peer reviewed and non-peer reviewed literature Monographs and other large format publications Existing databases such as the Paleobiology Database Fieldguides

Published and unpublished master's theses and doctoral dissertations

\section{Data integrity}

The sources for all taxonomic, stratigraphic and biogeographic data are documented on the Reference Form

A non-judgmental view is taken for the validity of taxonomic data. The taxonomy of a taxon is considered valid unless it is overridden by newer data

A non-judgmental view is taken for validity of al specimen identifications. The identification is considered valid unless overridden by newer data

A non-judgmental view is taken for the validity of all reported stratigraphic and biogeographic data. The reported data is considered valid unless it is overridden by newer data

Modern stratigraphic nomenclature is used whenever possible. If conversion to newer nomenclature is not possible or at all uncertain, the older stratigraphic nomenclature contained in the reference is used

\section{Database forms}

\section{Reference form}

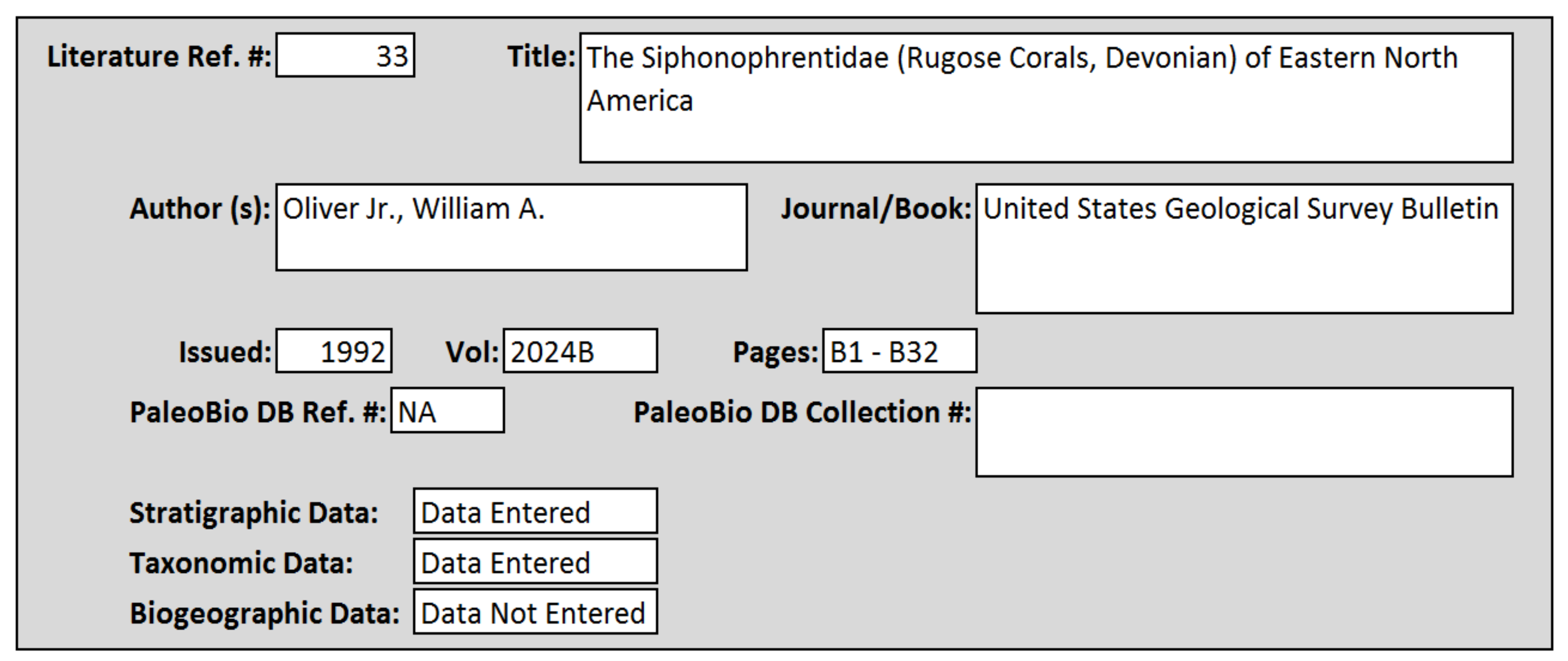

Taxon form

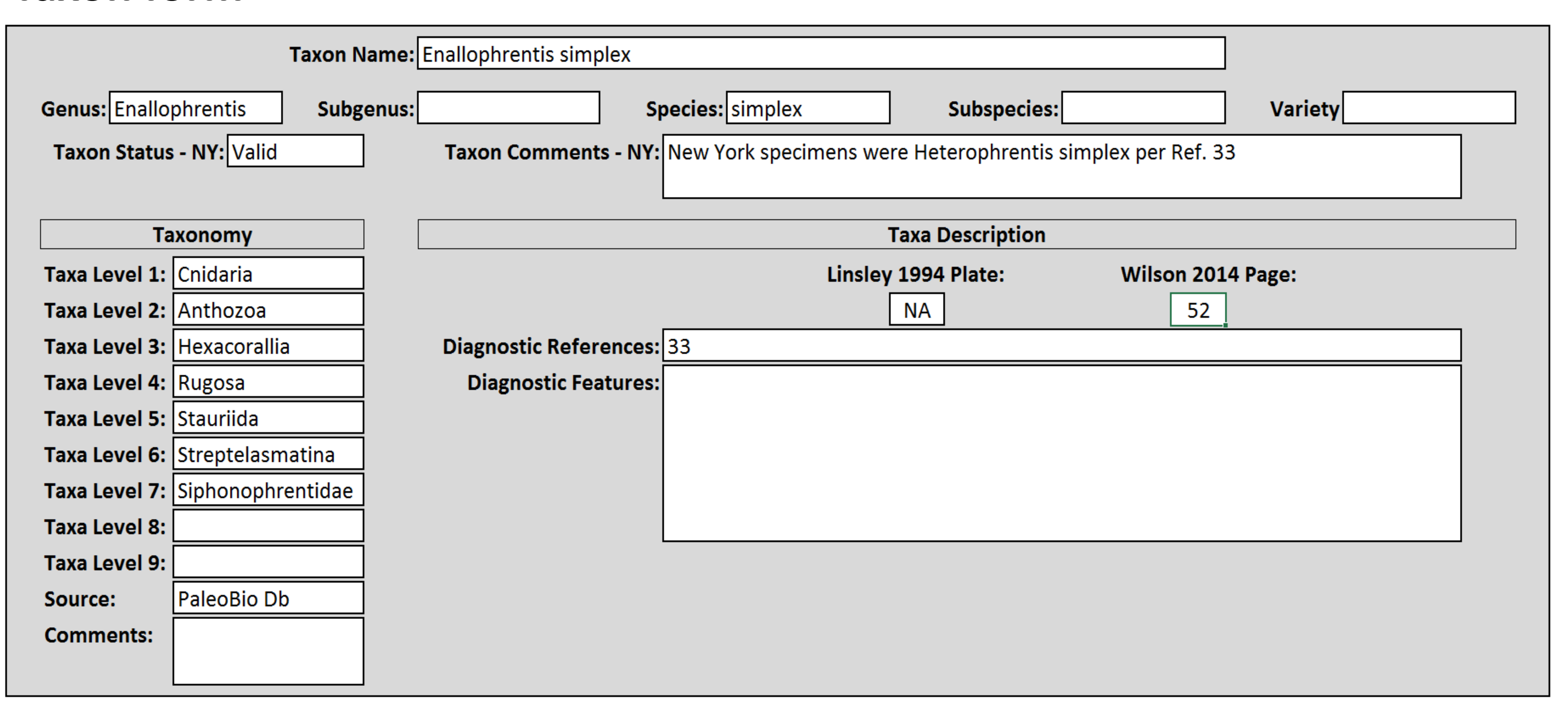

\section{Occurrence form}

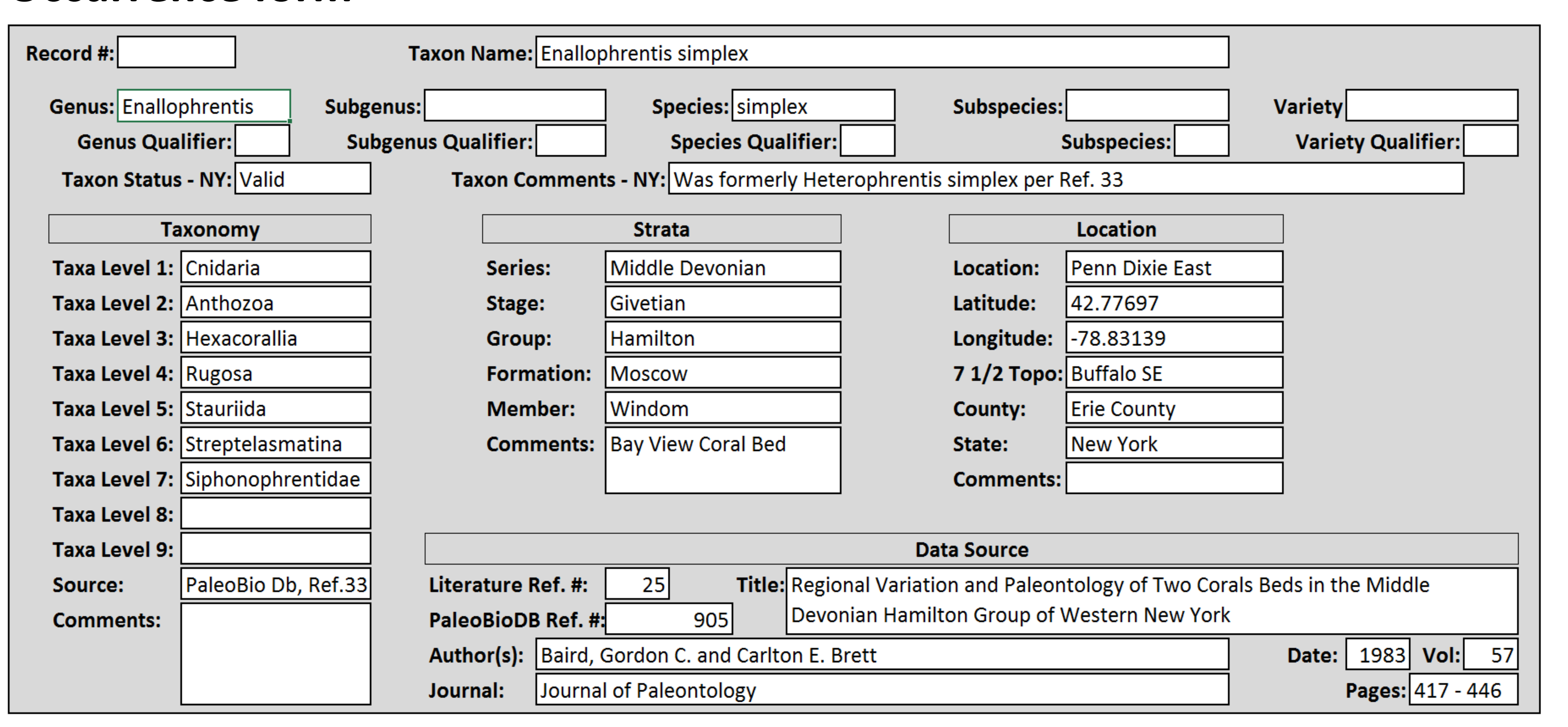

Data process flow

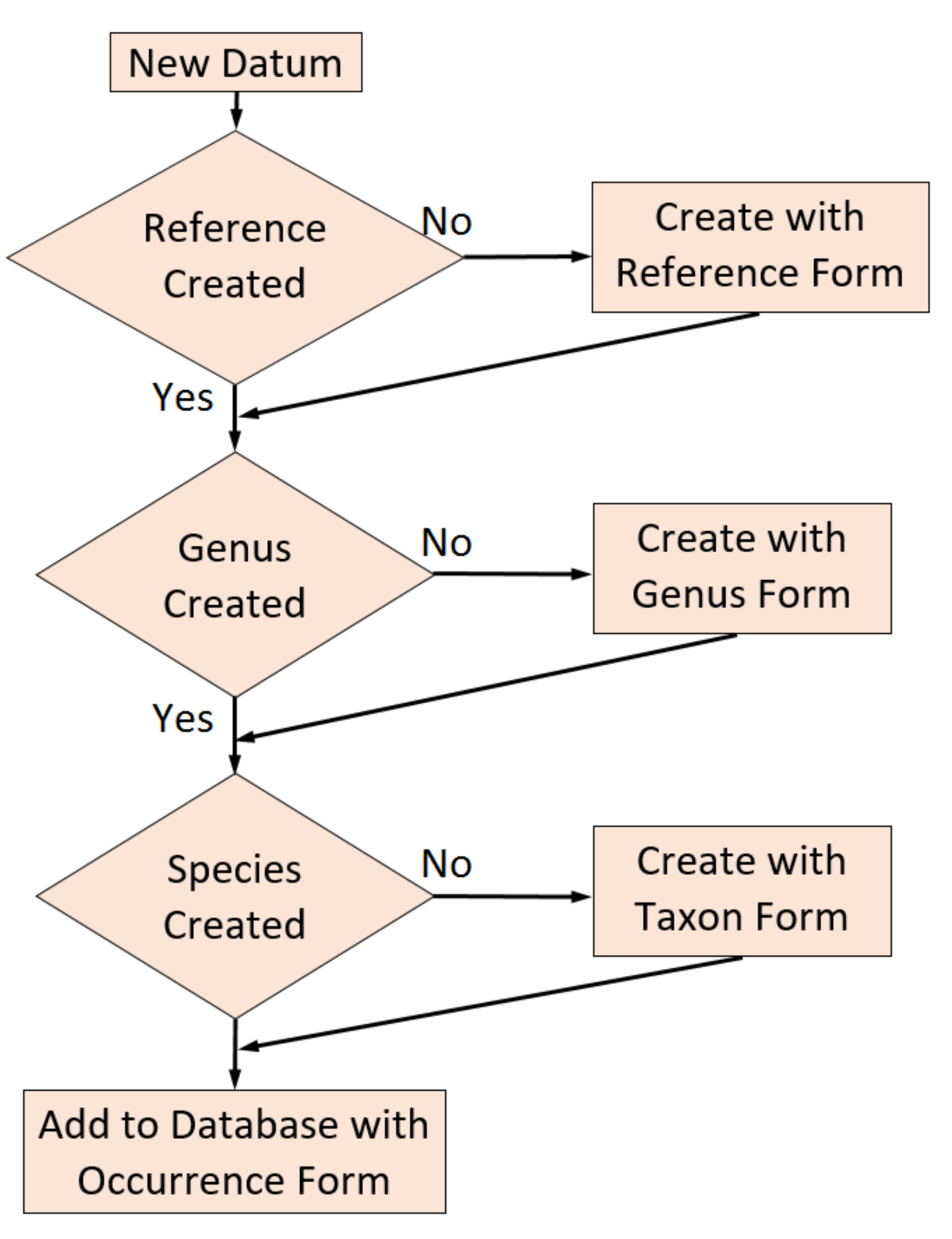

\section{Data input methods}

Data is commonly entered manually using one of the existing input forms but can also be entered by:

Excel file

ODBC file

Text file

dBASE file

\section{Database search and output}

Using existing or custom forms the database can be searched using any data field or combination of data fields

Output can be by a custom report or data can be exported

Excel file

ODBC file

Text file

dBASE file

PDF file 